\title{
GpX-like catalysis: real opportunity or a chimera?
}

Claudio Santi *, Francesca Mangiavacchi, Cecilia Scimmi, Lisa Della Rina, Gilda Troci, letizia Crociani, Luca Sancineto Group of Catalysis Synthesis and Organic Green Chemistry

Dpt Pharmaceutical Sciences University of Perugia Italy - claudio.santi@unipg.it
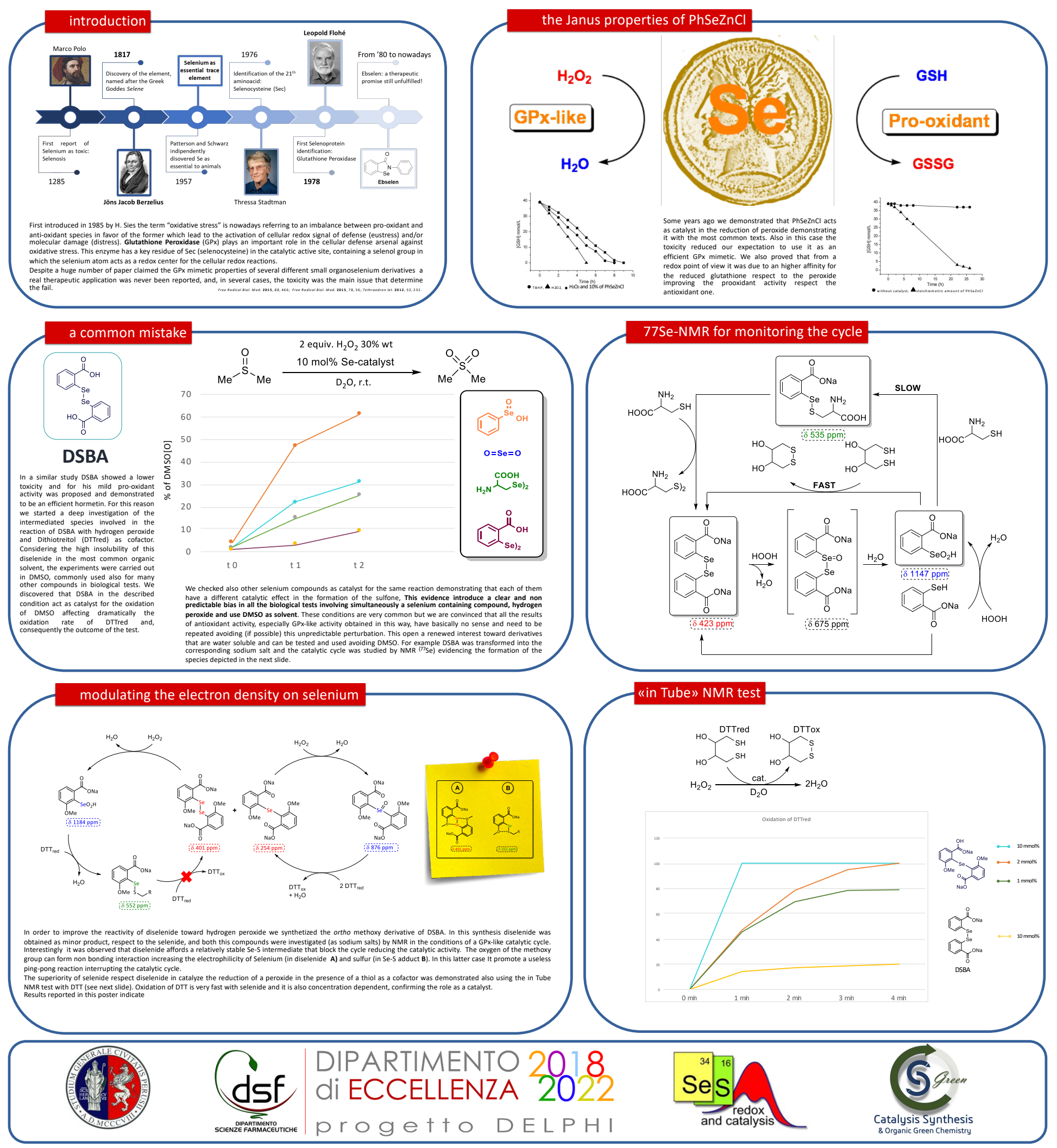